\title{
Gene delivery of TGF- $\beta 1$ induces arthrofibrosis and chondrometaplasia of synovium in vivo
}

\author{
Rachael S Watson ${ }^{1}$, Elvire Gouze ${ }^{1}$, Padraic P Levings ${ }^{1}$, Marsha L Bush ${ }^{1}$, Jesse D Kay ${ }^{1}$, Marda S Jorgensen ${ }^{2}$, \\ E Anthony Dacanay ${ }^{1}$, John W Reith ${ }^{3}$, Thomas W Wright ${ }^{1}$ and Steven C Ghivizzani ${ }^{1}$
}

To understand the cellular and molecular events contributing to arthrofibrosis, we used an adenovirus to deliver and overexpress transforming growth factor-beta 1 (TGF- $\beta 1$ ) CDNA (Ad.TGF- $\beta 1$ ) in the knee joints of immunocompromised rats. Following delivery, animals were killed periodically, and joint tissues were examined macroscopically and histologically. PCR-array was used to assay alterations in expression patterns of extracellular matrix (ECM)-associated genes. By days 5 and 10, TGF- $\beta 1$ induced an increase in knee diameter and complete encasement of joints in dense scar-like tissue, locking joints at $90^{\circ}$ of flexion. Histologically, massive proliferation of synovial fibroblasts was seen, followed by their differentiation into myofibroblasts. The fibrotic tissue displaced the normal architecture of the joint capsule and fused with articular cartilage. RNA expression profiles showed high levels of transcription of numerous MMPs, matricellular and ECM proteins. By day 30, the phenotype of the fibrotic tissue had undergone chondrometaplasia, indicated by cellular morphology, matrix composition and $>100$-fold increases in expression of collagen type II and cartilage link protein. Pre-labeling of articular cells by injection with recombinant lentivirus containing eGFP CDNA showed fibrotic/cartilaginous tissues appeared to arise almost entirely from local proliferation and differentiation of resident fibroblasts. Altogether, these results indicate that TGF- $\beta 1$ is a potent inducer of arthrofibrosis, and illustrate the proliferative potential and plasticity of articular fibroblasts. They suggest the mechanisms causing arthrofibrosis share many aspects with tumorigenesis.

Laboratory Investigation (2010) 90, 1615-1627; doi:10.1038/labinvest.2010.145; published online 9 August 2010

KEYWORDS: adhesive capsulitis; arthrofibrosis; chondrometaplasia; differentiation; frozen shoulder; synovium; transforming growth factor-beta 1

Arthrofibrosis is a condition that arises from the development of excess fibrous tissue intra-articularly, which leads to chronic joint pain and loss of range of motion. It can occur in most joints and frequently onsets following injury, surgery, diabetes or immobilization; however, the precise etiology remains unclear. $^{1-4}$ A particularly common example is adhesive capsulitis of the shoulder, also known as frozen shoulder syndrome. It is characterized by a painful fibrotic expansion of the synovium and joint capsule, which gradually results in the loss of active and passive motion of the joint. ${ }^{5,6}$ Although the disease is generally self-limiting, it can persist for 2-3 years, leaving patients disabled with limited use of the affected arm. ${ }^{5,7}$ As the underlying causes remain unknown, no specific pharmacologic or non-surgical therapy has been shown to cure arthrofibrosis or provide significant long-term benefit.
Pathologic fibrosis is a prominent feature of chronic disease in several organs, including the skin, liver, lung and kidney, and often begins with local injury and activation of normal repair mechanisms. ${ }^{8,9}$ Following tissue damage, there is a need for local synthesis of reparative connective tissue, which involves the migration of fibroblasts to the wound site and their proliferation. These cells then synthesize abundant levels of extracellular matrix (ECM) proteins, including collagens, proteoglycans and fibronectin. Many of these fibroblasts differentiate into myofibroblasts, which express high levels of $\alpha$-smooth muscle actin ( $\alpha$ SMA) that confers contractile activity to facilitate wound closure. In pathologic fibrosis, as the healing process loses its inflammatory component, there is no accompanying reduction in the myofibroblasts, as would occur during normal healing, and a

\footnotetext{
${ }^{1}$ Department of Orthopaedics and Rehabilitation, College of Medicine, University of Florida, Gainesville, FL, USA; ${ }^{2}$ Department of Molecular Genetics, University of Florida, Gainesville, FL, USA and ${ }^{3}$ Department of Pathology, College of Medicine, University of Florida, Gainesville, FL, USA

Correspondence: Professor SC Ghivizzani, PhD, Department of Orthopaedics and Rehabilitation, College of Medicine, University of Florida, P.O. Box 100137, 1600 SW Archer Road, Gainesville, FL 32610-0137, USA.

E-mail: ghivisc@ortho.ufl.edu

Received 16 February 2010; revised 25 June 2010; accepted 2 July 2010
} 
contractile fibrotic state persists. It is thought that mechanisms that continually stimulate myofibroblast differentiation, or conversely those that specifically inhibit apoptosis or phenotypic reversion in these cells, are responsible for their persistence and that of the fibrotic condition. ${ }^{10}$

Although the initiating causes of pathologic fibrosis are likely diverse, the protein factors that mediate wound healing and tissue repair are considered to have central roles. In this regard, transforming growth factor-beta 1 (TGF- $\beta 1$ ) has been implicated as a participant in a majority of fibrotic conditions. ${ }^{11}$ This pleiotropic cytokine induces a broad array of biological activities, such as cellular proliferation, differentiation, regulation of inflammation and tumor progression. ${ }^{12,13}$ TGF- $\beta 1$ is also a potent mediator of ECM protein synthesis, and its expression is increased in numerous fibrotic conditions. ${ }^{14}$

Active TGF- $\beta$ binds to a heteromeric receptor complex consisting of TGF- $\beta$ type I and type II receptors, and signals intracellularly through transcriptional activators, Smads 2 and 3, as well as Smad-independent pathways. Most of the profibrotic effects, fibroblast proliferation, myofibroblast differentiation, enhanced synthesis of matrix proteins and inhibition of collagen breakdown, are thought to be mediated through Smad signaling. ${ }^{15}$ Indeed, several ECM genes are direct Smad targets, including collagen types I, III, V, VI, VII and $\mathrm{X}$, and fibronectin. ${ }^{16-18}$ TGF- $\beta 1$ is also known to regulate expression of other proteins thought to drive fibrogenesis, including connective tissue growth factor (CTGF), which is often considered to be a downstream mediator of TGF- $\beta 1$ induced fibrosis. ${ }^{19}$

Whereas other fibrotic conditions have received considerable research attention, there are comparatively few reports regarding the pathogenesis of arthrofibrosis. This can be partially attributed to the scarcity of relevant animal models, as well as a lack of available human tissue from early-stage disease for detailed analysis. Arthroscopy, because of its invasiveness, is not a diagnostic tool and is only used to remove fibrotic adhesions from late-stage immobilized joints that have proven resistant to other forms of therapy. Few studies have addressed the involvement of specific growth factors in arthrofibrosis; however, using immunohistochemical staining and ELISA, increased levels of TGF- $\beta 1$ are found in synovial and capsular tissues and diffusely in the fibrotic ECM. ${ }^{7,20,21}$

We hypothesized that sustained over-production of TGF- $\beta 1$ intra-articularly drives chronic arthrofibrosis. To test this, we used a recombinant adenovirus to deliver and locally overexpress the cDNA for human TGF- $\beta 1$ in the joints of athymic nude rats and examined the effects of chronic stimulation on the local biology of the capsular tissues. Using this approach, we found TGF- $\beta 1$ gene transfer rapidly induced a severe and persistent fibrotic condition that encased and immobilized the injected joint. Histologic examination, as well as focused expression arrays of the joint tissues, suggests that the developing fibrotic tissue possesses many of the molecular features of an aggressive tumor. Important findings regarding the proliferative and plastic nature of resident capsular fibroblasts were also revealed.

\section{MATERIALS AND METHODS Vector Production}

The adenoviral vectors (Ad.GFP and Ad.TGF- $\beta 1$ ) used in this study originated from replication-deficient type 5 adenovirus lacking E1 and E3 loci. The cDNAs encoding either GFP or TGF- $\beta 1$ were inserted in place of the E1 region, with expression driven by the human cytomegalovirus early promoter/enhancer. ${ }^{22}$ High-titer suspensions of recombinant adenovirus were prepared by amplification in 293 cells, and purified using three consecutive $\mathrm{CsCl}$ gradients as previously described. ${ }^{23}$ Titers were determined by optical density at $260 \mathrm{~nm}$.

Vesicular stomatitis virus G-protein (VSV-G) pseudotyped lentiviral vectors were produced by transient transfection of 293FT cells using Lipofectamine (Invitrogen, Carlsbad, CA, USA), with the transducing vector, pCDH1-GFP IRES NEO; which was generated by insertion of the cDNA for GFP into the multiple cloning site on the pCDH1-vector, and the Virapower ${ }^{\mathrm{TM}}$ packaging plasmids containing gag-pol, Rev, and VSV-G protein envelope (Invitrogen), with expression driven by the human cytomegalovirus early promoter/enhancer. At 48 and $72 \mathrm{~h}$, the conditioned media were harvested, filtered through a $0.45 \mu \mathrm{m}$ filter (Steri-cup; Millipore, Billerica, MA, USA) and centrifuged at 20000 r.p.m. in a swinging bucket rotor for $2 \mathrm{~h}$. The viral pellets were resuspended in Opti-Mem (Invitrogen) and stored in $-80{ }^{\circ} \mathrm{C}$.

\section{Animals}

Experiments were carried out on 6- to 7-week-old male athymic nude rats and male Wistar rats weighing 150-170 g (Charles River Laboratories, Wilmington, MA, USA) housed two per cage with free access to standard laboratory food and water. All animal procedures were approved by the Institutional Animal Care and Use Committee of the University of Florida. Ad.TGF- $\beta 1$ or Ad.GFP was suspended in $50 \mu \mathrm{l}$ phosphate-buffered saline and injected into the joint space of the knee through the infrapatellar ligament. At periodic intervals after intra-articular injection, animals were killed by $\mathrm{CO}_{2}$ asphyxiation followed by thoracic puncture. The joint tissues were then harvested for analysis.

\section{Preparation of Total RNA}

Total RNA was isolated from treated and control synovial and capsular tissues using the RNeasy mini kit (Qiagen, Valencia, CA, USA). Briefly, tissues were harvested and stored in RNALater (Qiagen) until RNA extraction was performed, at which time the tissues were frozen in liquid nitrogen and pulverized using a mortar and pestle. The pulverized tissue was added to lysis Buffer RLT, homogenized using a 20-gauge needle, and RNA was harvested using RNeasy spin columns following manufacturer's protocol (Qiagen). 


\section{PCR Array}

The ECM and Adhesion Molecules PCR Array for rat (SABiosciences, Frederick, MD, USA) was used to examine the expression of over 80 related genes. One $\mu \mathrm{g}$ of RNA was DNase-treated and reverse-transcribed using the $\mathrm{RT}^{2}$ First Strand Kit following manufacturer's protocol (SABiosciences). The resulting cDNA template was mixed with SYBR Green PCR master mix (SABiosciences) and $25 \mu \mathrm{l}$ of the mixture was equally aliquoted into the 96-well plate already containing individual PCR primer sets. Differential analysis was performed using software provided by SABiosciences. Briefly, the $\Delta \Delta \mathrm{CT}$ method was used for data analysis to determine foldincrease and decrease in expression between treated and control tissues. The Student's $t$-test was used to determine statistical significance. Each time point represents $n=3$.

\section{Immunohistochemistry}

In all, $5 \mu \mathrm{m}$ sections of formalin-fixed, decalcified, paraffinembedded blocks were cut and mounted on plus charged slides (Fisher Scientific, Pittsburgh, PA, USA). Slides were deparaffinized and rehydrated through a series of xylenes and graded alcohols and blocked in 3\% peroxide/methanol for $10 \mathrm{~min}$ at room temperature. If required, heat-mediated antigen retrieval was performed in Dako Target Retrieval Solution (DakoCytomation, Carpinteria, CA, USA) for $20 \mathrm{~min}$ at $95{ }^{\circ} \mathrm{C}$. Nonspecific binding was blocked in $15 \%$ normal serum matched to the secondary antibody species. Slides were incubated overnight at $4{ }^{\circ} \mathrm{C}$ with commercially available antibodies: mouse anti- $\alpha$ SMA at 1:1000 dilution (Sigma, St Louis, MO, USA) (no retrieval), goat anti-MMP-9 at 1:50 (Santa Cruz Biotechnology, Santa Cruz, CA, USA), mouse anti-MMP-13 at 1:15 (Santa Cruz Biotechnology). The appropriate biotinylated secondary antibody (Vector Labs, Burlingame, CA, USA) was applied to samples for $30 \mathrm{~min}$ at room temperature at a dilution of 1:200, followed by detection with an avidin-biotin-based peroxidase kit (ABC Elite; Vector Laboratories). The antigen-antibody complex was observed by reaction with 3,3'-diaminobenzidine and slides were counterstained with hematoxylin and coverslipped.

For detection of GFP, $5 \mu \mathrm{m}$ sections collected from decalcified, paraffin-embedded blocks were manually immunostained using rabbit anti-GFP (dilution 1:1000, ab290; Abcam, Cambridge, MA, USA). Slides were heat retrieved in $10 \mathrm{mM}$ Citra Buffer, pH 6.0 before blocking with normal serum and staining overnight at $4{ }^{\circ} \mathrm{C}$. Positive signal was detected with anti-rabbit Alexafluor 488 (dilution 1:500; Molecular Probes, Eugene, OR, USA). Controls consisting of isotype and concentration-matched immunoglobulin were included for each section.

\section{RESULTS}

Intra-articular Delivery of Ad.TGF- $\beta 1$ Induces a

\section{Dose-Dependent Fibrotic Response}

Before undertaking in vivo experiments, we first characterized the Ad.TGF- $\beta 1$ vector for transgene expression in cultures of synovial fibroblasts isolated from the joints of rats. The cells were incubated with increasing doses of virus, and $48 \mathrm{~h}$ later, the levels of human TGF- $\beta 1$ in the conditioned media were determined by specific ELISA. As shown in Figure 1, TGF- $\beta 1$ was expressed in a dose-dependent manner and achieved a maximum of $\sim 1 \mu \mathrm{g} / \mathrm{ml}$ at $2.0 \times 10^{9}$ viral particles (v.p.). Vector doses exceeding this were found to be toxic to the cells.

After confirming the ability of the Ad.TGF- $\beta 1$ construct to deliver and express the transgene in the target cells, we performed preliminary studies in vivo to determine a vector dose that would provide a significant biological response without being detrimental to the health of the animals when expressed long term. We initially used Wistar rats, which are immunologically competent, but enable sustained expression of adenovirally delivered transgenes for about 7-10 days. ${ }^{24}$ For these experiments, groups of rats were injected in both knees with low $\left(1.0 \times 10^{9}\right.$ v.p. $)$, medium $\left(2.0 \times 10^{9}\right.$ v.p. $)$ or high $\left(4.0 \times 10^{9}\right.$ v.p. $)$ doses of virus. Rats receiving $4.0 \times 10^{9}$ v.p. of Ad.GFP were used as controls for the pathological effects of viral delivery. The experiment was scheduled for 7 days, at which time the animals would be killed and the tissues harvested for analysis.

Within 3 days, the knees receiving the Ad.TGF- $\beta 1$ virus became visibly enlarged, increasing in size with the vector dose. At 4 days post-injection, the rats receiving the highest dose of Ad.TGF- $\beta 1$ were killed because of health concerns. They were lethargic, did not eat and showed labored respiration. Although the animals at the lower doses showed a prominent increase in joint diameter, they were otherwise healthy with normal appetite. Dissection of the joints from the animals killed at day 4 , and those of the remaining groups

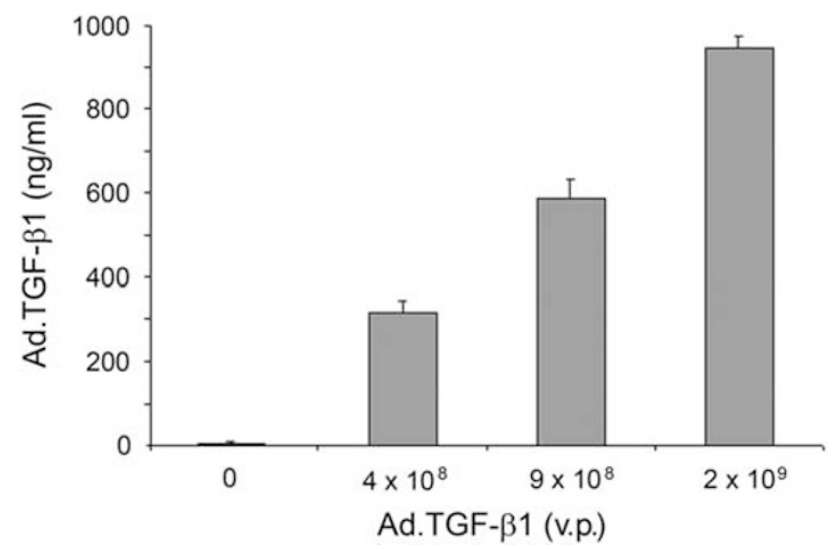

Figure 1 Transgene expression following infection of rat synovial fibroblasts with Ad.TGF- $\beta 1$. After isolation of fibroblasts from rat synovium, the cells were grown in monolayer in 12-well plates and infected with increasing doses of Ad.TGF- $\beta 1$. At $24 \mathrm{~h}$ post-infection, the medium was replaced by $0.5 \mathrm{ml}$ of serum-free medium. At $48 \mathrm{~h}$ post-infection, the conditioned medium was harvested and TGF- $\beta 1$ content measured by specific ELISA. Results are expressed in $\mathrm{ng} / \mathrm{ml}$ as the mean of three replicates. Error bars represent \pm s.e.m. v.p. $=$ viral particles. 
killed at day 7 , showed that the increase in joint size was due to the overgrowth of a dense scar-like tissue that encased the joints and effectively occluded joint motion.

\section{Sustained Overexpression of TGF- $\beta 1$ in the Joints of Nude Rats Induces Severe Arthrofibrosis and Chondrometaplasia}

After observing the initial fibrotic response to overexpression of Ad.TGF- $\beta 1$ and identifying a working range of virus, we next wanted to determine the effects of sustained TGF- $\beta 1$ overexpression for a prolonged period of time. We injected the medium dose $\left(2.0 \times 10^{9}\right.$ v.p. $)$ of Ad.TGF- $\beta 1$ into both knee joints of a group of nude rats. As a control for viral administration, we delivered a similar dose of Ad.GFP into a parallel group. Animals in each group were euthanized at 5,10 and 30 days post-injection and the joint tissues were harvested for analysis.

As seen in Figure 2, by day 5 the knee joint diameter in the animals receiving Ad.TGF- $\beta 1$ increased by about $40 \%$ relative to controls, which was maintained throughout the course of the experiment. Following euthanization and removal of the skin, gross inspection showed that the knee joints were completely enveloped in fibrotic tissue such that the normal features of the joint were not discernable (similar to that shown in Figure 3c). Consistent with the pilot experiments, by day 5 the knee joints had become immobilized, and remained locked at $90^{\circ}$ flexion for the duration of the experiment. During dissection of the day 5 animals, the fibrotic encasement was easily cut from the bone to expose

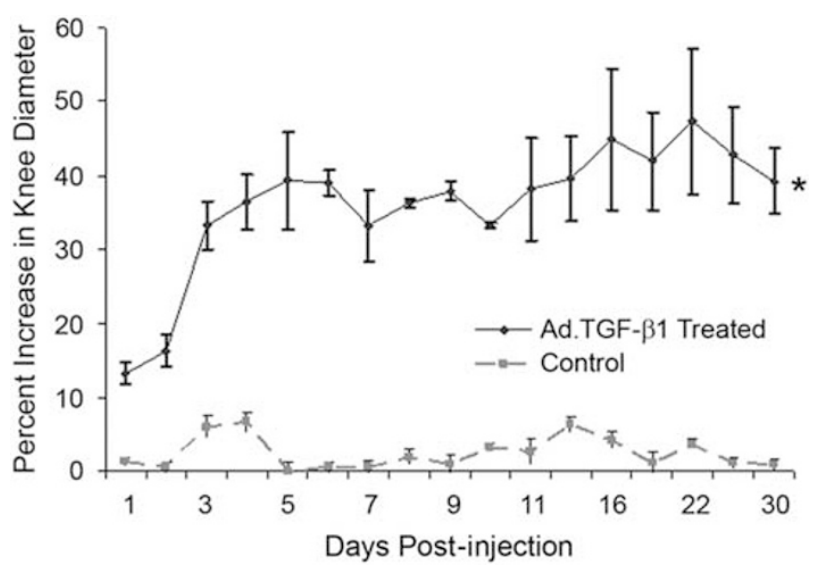

Figure 2 Intra-articular delivery of Ad.TGF- $\beta 1$ induces joint swelling. The knees of nude rats were injected with $2.0 \times 10^{9} \mathrm{v}$.p. of Ad.TGF- $\beta 1$ or Ad.GFP as a negative control, and the diameter of the joints was measured periodically with calipers. Injection of Ad.TGF- $\beta 1$ rapidly induced joint thickening, and all animals showed increased knee diameter throughout the experiment. For the Ad.TGF- $\beta 1$-treated group, days 0 and 5 represent $n=16$ knees, days 5-10 represent $n=8$ knees and days $10-30$ represent $n=4$ knees. For all time points Ad.GFP control represents an $n=8$ knees. Values represent the mean of measurements for all knees in each group. Error bars represent \pm s.e.m. All points in treated animals were statistically significant compared with control as indicated with an asterisk (one-way ANOVA, $P<0.05)$. the intact structures beneath. At each successive time point, however, the fibrotic tissue became progressively more dense, such that by day 30 it appeared to penetrate and fuse with the bony architecture of the knee joint, making it difficult to distinguish pre-existing anatomy (Figure 3d).

Histologic analysis of the harvested tissues showed that injection of Ad.GFP caused a slight increase in the number of leukocytes in the synovial intima at day 5 , but otherwise the tissues appeared normal (Figure 4, control). In stark contrast, injection of Ad.TGF- $\beta 1$ stimulated a dramatic fibrotic response intra-articularly that, over time, changed and progressed into an aggressive fibrocartilaginous metaplasia. By day 5, there was an extensive proliferation of reactiveappearing stellate and spindled fibroblasts effacing much of the normal intra- and periarticular connective tissues (Figure 4, day 5). The fibroblasts replaced the normal subsynovial adipose tissue, and radiated outward from the joint space without altering the articular cartilage, which maintained its amphophilic appearance on toluidine blue stains. The fibroblastic proliferation also extended into adjacent skeletal muscle, in which it invaded between myocytes. There was little accompanying inflammatory component early and no metaplastic bone or cartilage was identified at 5 days.

At 10 days, the fibroblastic proliferation had essentially replaced all of the normal anatomic structures in and surrounding the joint and began to fuse with articular cartilage, subperiosteal cortical bone, and ligamentous and capsular fibrous tissue (Figure 4, day 10). At these sites of fusion, the cells began to lose their once spindled morphology, instead appearing as rounded, chondrocyte-like cells.

At 30 days, the normal microscopic anatomy of the joint was not recognizable and the resident joint and capsular structures were displaced (Figure 4, day 30). The fibroblastic component was considerably less cellular and more densely fibrotic, and large areas were now composed of cartilaginous tissue. The majority of the articular cartilage was replaced by metaplastic fibrocartilaginous tissue, confirmed by the deeply amphophilic appearance of the tissue on toluidine blue stain. There was no clear delineation between the fibrous component and the cartilaginous component. These cartilaginous masses penetrated the entire joint space leaving an abundant deposition of matrix enriched for proteoglycans.

\section{TGF- $\beta 1$ Stimulates Expression of Genes for Matricellular} Proteins, MMPs, Collagens and Adhesion Molecules

In an attempt to determine the protein mediators responsible for driving the pathologic changes in the cells and tissues, RNA isolated from the capsular/synovial tissues of control rats and those receiving Ad.TGF- $\beta 1$ was analyzed by PCRarray for differential expression of 84 genes associated with cellular adhesion, ECM synthesis and remodeling.

Differential analyses of the expression patterns, as seen in Table 1, strikingly illustrates the extent to which prolonged exposure to TGF- $\beta 1$ activates the articular tissues. Numerous genes showed significantly enhanced expression, many 

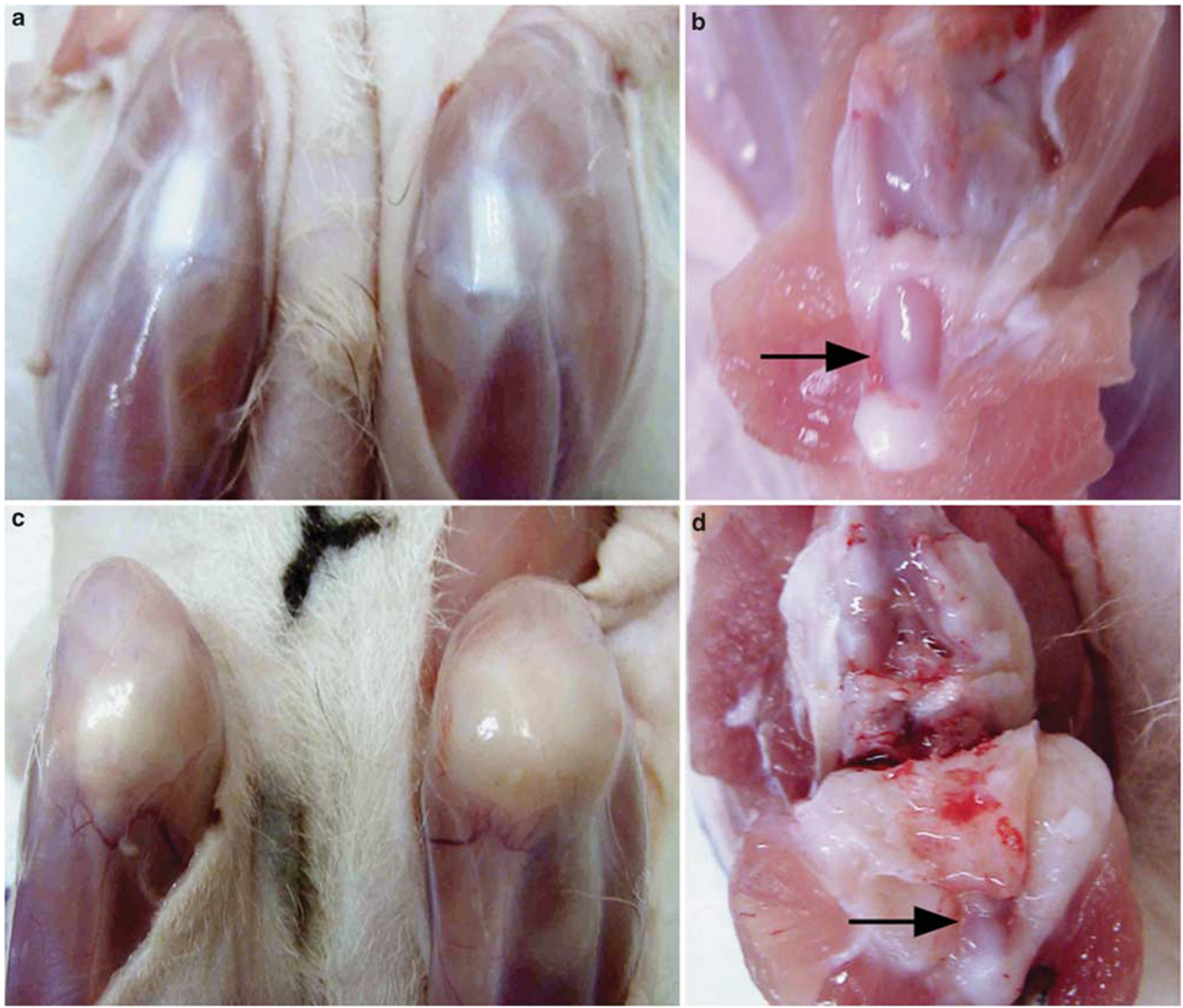

Figure 3 Local overexpression of Ad.TGF- $\beta 1$ in the knee joint induces severe arthrofibrosis. The knees of nude rats were injected bilaterally with $2.0 \times 10^{9}$ v.p. of Ad.TGF- $\beta 1$ or Ad.GFP (as a negative control). Groups of three animals were killed at days 5,10 and 30 and the joints ( $n=6$ per vector and time point) were analyzed for the effects of transgene expression. Images shown are representative of animals killed at day 30. (a, c) External views of knee joints after removal of the skin. (b, d) Internal views of the joints following dissection. For joints receiving Ad.TGF- $\beta 1$ there was a visible increase in joint size, and the knees became encased in a dense, scar-like tissue. On dissection, the fibrotic tissue was observed to override the joint space and displace preexisting structures. Arrows indicate the location of the patella.

exceeding 100-fold, while only modest reductions in expression were observed sporadically in a handful of the genes. Analyzed over the course of the experiment, the most extensive and consistent changes in gene expression were observed among the collagens, the matricellular proteins and the proteolytic enzymes.

Consistent with the early fibrotic expansion, collagen types I, III and V were elevated from 3- to 10-fold at days 5 and 10 . As the hypercellular tissue began to differentiate and transition to a cartilaginous phenotype at day 10, expression of collagen type II and hyaluronan and proteoglycan link protein 1 (HAPLN1/cartilage link protein) dramatically increased, with both genes showing $>100$-fold increase by day 30. Modest increases in expression of collagens VI and VIII were also observed at different time points.

Supporting the highly proliferative, expansive response of the capsular tissues, expression of the matricellular protein genes, as a group, was elevated at all time points. Those most profoundly induced were osteopontin (30- to 100-fold), followed by thrombospodins 1 and 2, tenascin-C and periostin. Expression of other matricellular protein genes, such as CTGF and secreted protein acidic and rich in cysteine (SPARC/osteonectin), was also modestly elevated throughout the study and only achieved statistical significance at certain time points.

Characteristic of the expansive and invasive properties of the capsular tissues, expression of the MMPs was broadly 

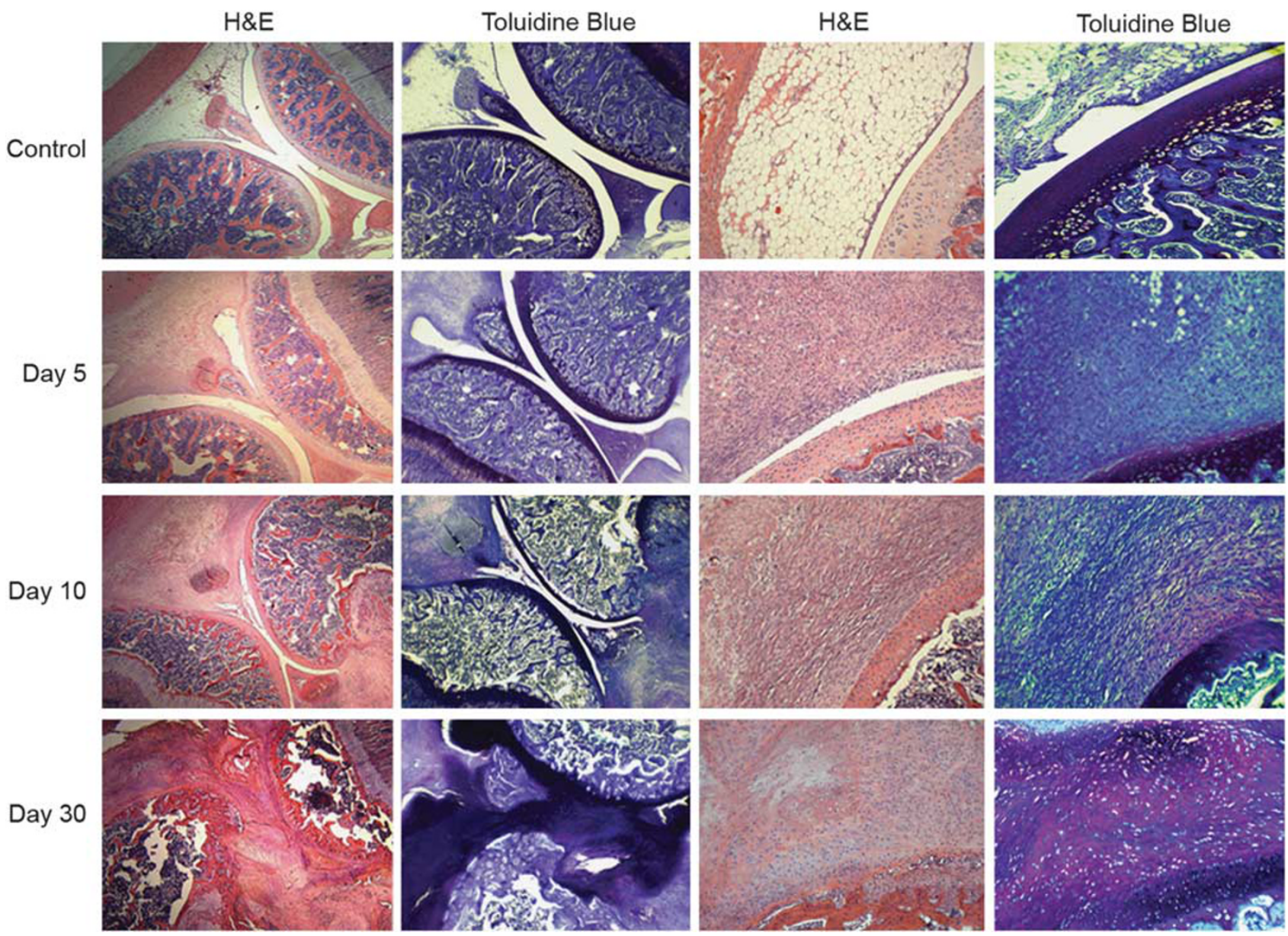

Figure 4 Synovial capsular fibrosis and chondmetaplasia induced by Ad.TGF- $\beta 1$. The knees of nude rats were injected bilaterally with $2.0 \times 10^{9}$ v.p. of Ad.TGF- $\beta 1$ or Ad.GFP (as a negative control). Groups of three animals were killed at days 5,10 and 30 and the joints $(n=6$ per vector and time point) were harvested, decalcified and processed for histology. Sections were stained with H\&E or toluidine blue as indicated. Control images show Ad.GFP treated joints at day 5, but are representative of all time points. These sections appeared largely normal with a slight increase in the number of leukocytes. At 5 days post-injection of Ad.TGF- $\beta 1$, expansion of spindled fibroblasts from the synovial lining and joint capsule produced a fibrotic mass, occluding the underlying adipose layer. At 10 days post-injection, the fibrotic tissue expanded to replace all normal structures and began to fuse with articular cartilage, in which the development of rounded chondrocytic cells can be seen. By day 30, the hypertrophied tissue became highly aggressive and filled the entire joint space, displacing the normal architecture. The bulk of the fibrotic expanse differentiated into a cartilaginous phenotype as indicated by the cellular morphology and toluidine blue staining. The normal articular cartilage was replaced by metaplastic fibrocartilaginous tissue, which also invaded the subchondral and periarticular bone. Images in left two columns are at $\times 2.5$ magnification, and images in the right two columns are at a magnification of $\times 20$.

induced at all time points. Expression of MMP-12 (elastase) showed the greatest sustained induction ranging from $\sim 100$ - to 200 -fold over controls. This was followed by the collagenases, MMPs-13 and -8 , which were also elevated throughout the experiment, but showed $>200$-fold enhanced expression at days 10 and 30, respectively. MMPs-9 and -2 (the gelatinases), MMP-7 (matrilysin), MMP-11 (a member of the stromelysin family) and MMPs-14 and -16 (also termed membrane type; MT-MMPs-1 and -3) also showed significant increases in expression, ranging between $\sim 3$ - and 80 -fold induction throughout the course of the experiment. ADAMTS1 showed evidence of enhanced expression at each time point, but this was not statistically significant.

A variety of cellular adhesion molecules also showed increased expression in the expanded capsular tissues. It is noteworthy that E-, N- and P-cadherins (epithelial, neural and placental, respectively) were each upregulated at day 5; however, only $\mathrm{N}$-cadherin remained highly expressed for all 30 days. Interestingly, this was paralleled by heightened expression of neural-cell adhesion molecule (NCAM). Both NCAM and N-cadherin are thought to coordinately interact during cellular condensation in chondrocytic differentiation as well as in tumor cell proliferation. Several integrin receptor molecules showed increased expression during the early stages of the experiment, including $\alpha_{\mathrm{L}}$ and $\beta_{3}$ subunits at day 5 , and $\alpha_{\mathrm{L}}, \alpha_{\mathrm{M}}, \beta_{2}$ and $\beta_{3}$ at day 10 . Increased expression of $\beta$-catenin was also seen at day 10 and L-selectin showed $\sim 16$-fold enhanced expression at day 30 .

Several other genes showed enhanced expression; the most notable being Emilin-1 whose expression was increased 
Table 1 Relative expression values of ECM and associated genes in the joints of nude rats receiving Ad.TGF- $\beta 1$

Gene Day $5 \quad$ Day $10 \quad$ Day 30

Structural proteins

Collagen, type 1, alpha 1

Collagen, type 2, alpha 1

Collagen, type 3, alpha 1

Collagen, type 4, alpha 1

Collagen, type 4, alpha 2

Collagen, type 4, alpha 3

Collagen, type 5, alpha 1

Collagen, type 6, alpha 1

Collagen, type 8, alpha 1

HAPLN 1

Versican

Matricellular proteins

\section{CCN2/CTGF}

Osteopontin 1

Periostin

SPARC

Spock 1

Tenascin-C

Thrombospondin 1

Thrombospondin 2

Cell adhesion proteins

E-cadherin

$\mathrm{N}$-cadherin

P-cadherin

R-cadherin

Catenin, alpha 1

Catenin, alpha 2

Catenin, beta 1

Contactin 1

Icam-1

Integrin, alpha 2

Integrin, alpha 3

Integrin, alpha 4

Integrin, alpha 5

Integrin, alpha D

Integrin, alpha E

Integrin, alpha L

Integrin, alpha $M$

Integrin, alpha V

Integrin, beta 1

Integrin, beta 2

Integrin, beta 3

Integrin, beta 4

NCAM 1

NCAM 2

Pecam

Day 5

\begin{tabular}{rrr}
4.5 & $9.7^{\star}$ & 3.7 \\
6.4 & $160.3^{\star}$ & $223.3^{\star}$ \\
1.8 & 6.1 & 1.9 \\
1.1 & 2.3 & $-\underline{2.1}$ \\
1.1 & 4.2 & -1.1 \\
$-3.1^{\star}$ & -1.7 & -2.6 \\
\hline $4.0^{*}$ & 5.8 & 2.6 \\
1.7 & 4.8 & 2.2 \\
7.6 & 5.1 & 3.3 \\
2.3 & $33.8^{\star}$ & $106.5^{\star}$ \\
$4.6^{*}$ & 2.9 & 4.5
\end{tabular}

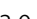

$32.8^{*}$

3.6

$9.3^{*}$

$9.3^{+}$

2.8

1.4

$9.5^{*}$

$26.1^{*}$

$12.6^{*}$

$118.0^{*}$

4.4

$130.0^{*}$

$6.9^{*}$

$$
7.3
$$$$
2.1
$$

7.4

3.7

$8.9^{*}$

1.4

$9.6^{*}$

$20.0^{*}$

$14.5^{*}$

$8.8^{*}$

$4.5^{\star}$

$10.7^{\star}$

$8.4^{\star}$

$-\frac{5.4}{1.2}$

1.7

2.0

$-\underline{3.2}$

$-1.0$

$-1.1$

$-1.8$

1.2

1.8

1.5

1.6

2.6

1.5

1.4

2.2

1.5

2.3

$-1.5$

$25.3^{*}$

1.3

$-1.0$
Table 1 Continued

\begin{tabular}{|c|c|c|c|}
\hline Gene & Day 5 & Day 10 & Day 30 \\
\hline E-selectin & 1.4 & -1.7 & 1.8 \\
\hline L-selectin & 3.6 & 14.3 & $15.83^{\star}$ \\
\hline P-selectin & 2.2 & 3.1 & 2.0 \\
\hline VCAM 1 & -2.0 & 1.2 & -1.7 \\
\hline Vitronectin & -1.8 & 1.3 & -2.3 \\
\hline \multicolumn{4}{|l|}{ Extracellular matrix proteins } \\
\hline Fibronectin 1 & 1.3 & 3.4 & 2.7 \\
\hline Laminin alpha 1 & 5.7 & 5.1 & $25.0^{*}$ \\
\hline Laminin alpha 2 & -2.2 & 2.3 & 1.4 \\
\hline Laminin alpha 3 & 1.1 & 3.5 & -1.3 \\
\hline Laminin beta 2 & -2.4 & 3.5 & -1.4 \\
\hline Laminin beta 3 & -1.5 & 3.8 & 2.9 \\
\hline Laminin gamma 1 & 21.6 & 72.4 & 3.3 \\
\hline Tgfbi & $6.9^{*}$ & 9.3 & $3.9^{*}$ \\
\hline \multicolumn{4}{|l|}{ Metaolloproteinases and inhibitors } \\
\hline ADAMTS 1 & 12.2 & 26.7 & 15.3 \\
\hline ADAMTS 2 (RGD1565950) & 2.0 & $4.3^{*}$ & 3.8 \\
\hline ADAMTS 5 & -1.0 & 2.3 & 1.3 \\
\hline ADAMTS 8 & $-\underline{4.4}$ & -2.4 & -3.9 \\
\hline MMP 1a & 3.5 & 3.6 & 2.6 \\
\hline MMP 2 & $5.7^{\star}$ & $9.3^{*}$ & $6.3^{*}$ \\
\hline MMP 3 & -1.1 & 2.0 & 4.6 \\
\hline MMP 7 & $13.2^{*}$ & $20.8^{\star}$ & 9.0 \\
\hline MMP 8 & 10.4 & 229.9 & 39.2 \\
\hline MMP 9 & 11.0 & 79.5 & 3.1 \\
\hline MMP 10 & 3.2 & 11.2 & 8.3 \\
\hline MMP 11 & 2.9 & $17.9^{*}$ & $4.4^{*}$ \\
\hline MMP 12 & $97.3^{*}$ & $182.9^{*}$ & $198.1^{\star}$ \\
\hline MMP 13 & 19.3 & 58.9 & 300.3 \\
\hline MMP 14 & $7.0^{*}$ & $5.0^{*}$ & $6.4^{*}$ \\
\hline MMP 15 & -1.4 & 1.3 & $-\underline{-2.1}$ \\
\hline MMP 16 & 3.2 & 9.6 & $5.70^{*}$ \\
\hline TIMP 1 & $10.8^{\star}$ & 1.1 & $6.8^{*}$ \\
\hline TIMP 2 & 2.9 & 1.5 & 2.5 \\
\hline TIMP 3 & $-\underline{4.1^{*}}$ & 3.1 & -1.5 \\
\hline \multicolumn{4}{|l|}{ Elastic fiber proteins } \\
\hline Emilin 1 & $181.3^{\star}$ & 87.0 & 36.1 \\
\hline Fibulin 1 & 1.4 & 3.4 & 3.1 \\
\hline Extracellular matrix protein 1 & -1.5 & 3.8 & 1.5 \\
\hline \multicolumn{4}{|l|}{ Other } \\
\hline Synaptotagmin I & 3.1 & 3.0 & 9.2 \\
\hline CD44 antigen & -2.4 & -1.5 & -3.1 \\
\hline Sarcogycan & 1.3 & 3.4 & 1.1 \\
\hline NTPDase-1 (CD39) & 1.9 & 3.0 & 1.6 \\
\hline
\end{tabular}

Values shown in bold represent increases in gene expression at $P<0.05$. Values underlined represent decreases in gene expression at $P<0.05$. Values with an asterisk represent $P<0.01$. $n=3$ for each time point. 
$>180-$, 87- and 36-fold at days 5, 10 and 30. Emilin-1 is a connective tissue glycoprotein associated with elastic fibers, and is thought to contribute to cell motility, tissue differentiation and morphogenesis. ${ }^{25}$ Certain laminins also showed increased expression, particularly the laminin $\alpha 1$ chain at day 30 and laminin $\gamma 1$ at day 10 . Fibronectin was also moderately enhanced at days 10 and 30 .

To solidify these data, we used immunohistochemistry to examine the tissues for the presence of MMP-13 and MMP-9 at the protein level, as well as $\alpha \mathrm{SMA}$, a myofibroblast marker (Figure 5). Consistent with the expression patterns above, staining for MMP-13 was visible throughout the fibrotic matrix at the later time points, with darker staining in the more cartilaginous tissues. Similarly, staining for MMP-9 was consistent with RNA analysis and appeared throughout the fibrotic synovium. The darkest staining was observed at day 10 at the borders between the newly expanded fibrotic tissues and cartilaginous regions. As expected, dark staining for $\alpha$ SMA was detected at day 5 in the heavily fibrotic regions. ${ }^{26}$ At days 10 and 30 , as the cells appeared to differentiate toward a chondrocytic phenotype, $\alpha \mathrm{SMA}$ staining was significantly reduced.

\section{Resident Synovial/Capsular Fibroblasts Proliferate to form the Fibrotic Mass}

In fibrotic conditions of tissues, such as liver, lung and kidney, a level of uncertainty has surrounded the origin of the fibroblastic cells causing the pathology. In certain models, it remains unresolved as to whether the fibrosis arises from the local proliferation and differentiation of resident fibroblasts or from infiltrating progenitor cells originating from bone marrow or elsewhere.

To determine the origin of the cells responsible for generating the pathologic fibrotic and cartilaginous tissues in the joint, a lentiviral vector containing the cDNA for GFP (LV-GFP), was injected into the knees of nude rats $48 \mathrm{~h}$ before injection of Ad.TGF- $\beta 1$. We have shown previously that lentivirus-based vectors, when delivered at sufficient titer, will transduce a significant proportion of the fibroblastic cells resident in the normal joint. ${ }^{27}$ Therefore, by using a lentivirus to deliver the cDNA for GFP we could stably mark the fibroblastic cells that were pre-existent in the capsular tissues; furthermore, because the lentiviral vector integrates its genetic payload into the genome of the transduced cell, any progeny that arise from the transduced cell will similarly contain the transgene and fluoresce green. ${ }^{27,28}$ By prelabeling the resident capsular cells in this manner, if the cells comprising the fibrotic mass arise from resident fibroblast populations, then a large percentage should fluoresce green. Alternatively, if the fibroblastic cells arise from circulating myofibroblasts or progenitor cells, then the bulk of the cell mass would be negative for GFP expression.

Consistent with earlier experiments, delivery of LV-GFP in normal control joints, generated a uniform layer of fluorescent cells across the entire expanse of the synovial lining and penetrated several cell layers deep (Figure 6a). ${ }^{27,28}$ In the joints of animals that subsequently received Ad.TGF- $\beta 1$, examination at day 5 showed that the entire depth of the fibrotic synovial tissue was filled with elongated fluorescent fibroblastic cells. At day 10, the cells appeared

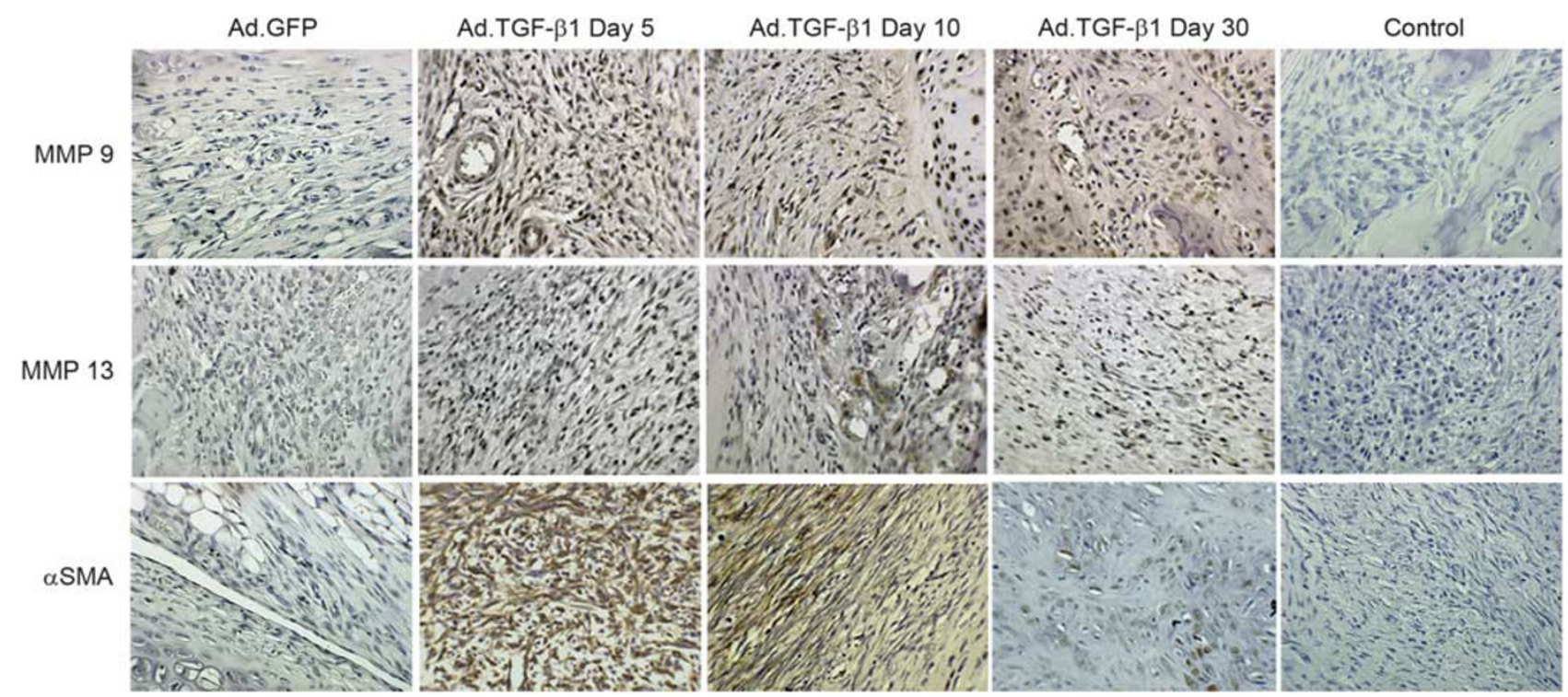

Figure 5 Immunohistochemical staining for MMPs-9 and -13 , and $\alpha$ smooth muscle actin $\left(\alpha\right.$ SMA). The knee joints of nude rats receiving $2.0 \times 10^{9}$ v.p. of either Ad.GFP or Ad.TGF- $\beta 1$ were harvested at days 5, 10 and 30, paraffin embedded, sectioned and immunohistochemically stained for the presence of MMP-9, MMP-13 or $\alpha$ SMA as indicated. Stained sections from joints receiving Ad.GFP are from day 5 post-injection, but are representative of all time points. Control sections shown are from joints receiving Ad.TGF- $\beta 1$, but were not incubated with the respective primary antibodies so as to rule out nonspecific staining from the secondary conjugated antibodies. 

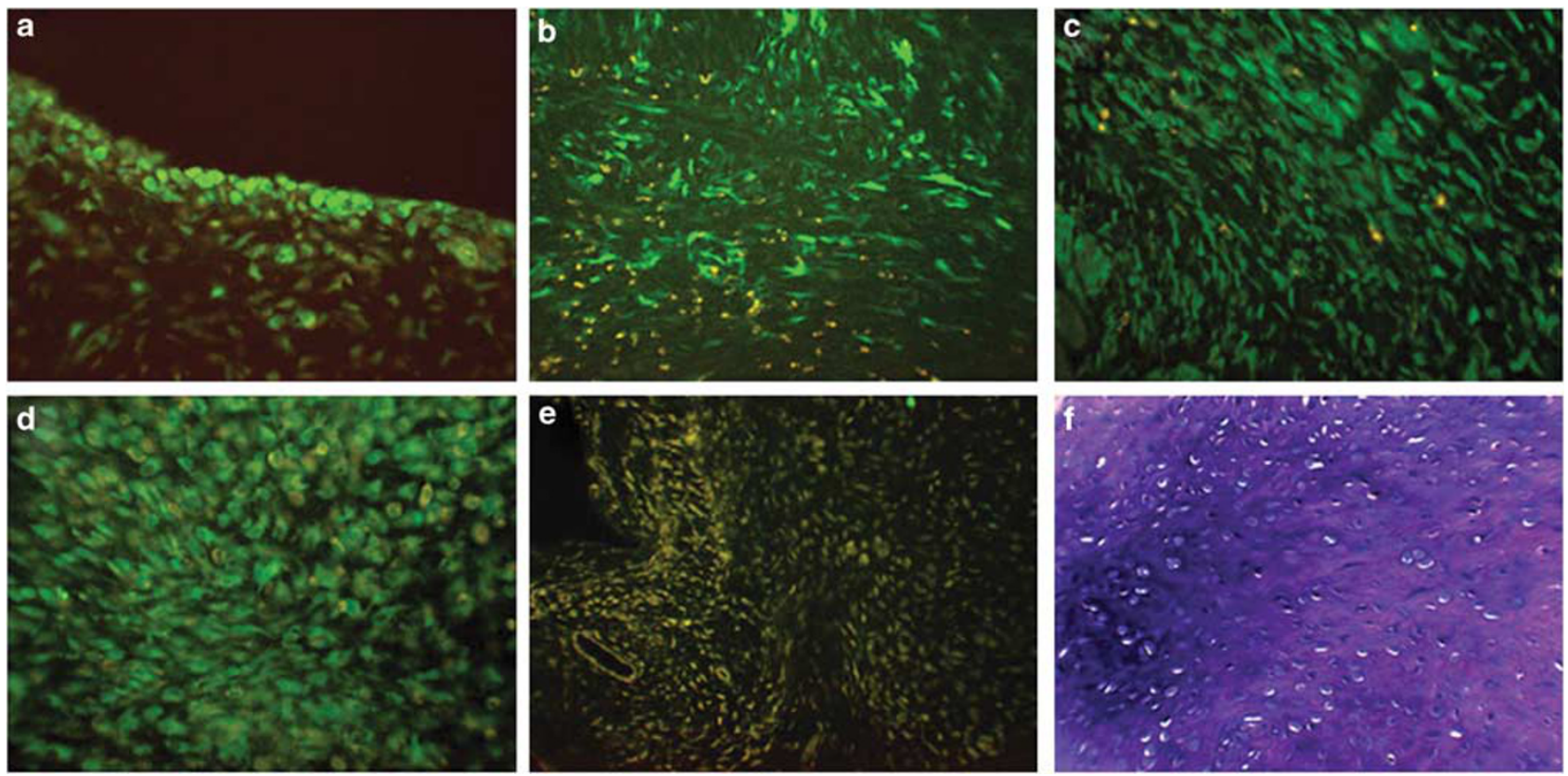

Figure 6 Arthrofibrosis and chondrometaplasia arise from resident synovial and capsular fibroblasts. (a) Fibroblastic cells in the synovium and joint capsule of nude rats were fluorescently labeled following intra-articular injection of recombinant lentivirus containing the cDNA for GFP (LV-GFP). At $48 \mathrm{~h}$ after delivery of LV-GFP, Ad.TGF- $\beta 1$ was injected into the joint, and the rats were killed periodically thereafter. (b) Day 5 post-Ad.TGF- $\beta 1$ injection showed a fibrotic cell mass composed primarily of GFP + cells. (c) At day 10, the GFP labeled cells began to acquire a chondrocytic appearance. (d) By day 30 , the GFP + cells had differentiated into a chondrocytic phenotype as evidenced by the rounded morphology. (e) Joints receiving only Ad.TGF- $\beta 1$ showed no evidence of GFP expression. (f) The cartilaginous phenotype of tissues in panel (d) is confirmed by metachromatic staining of proteoglycan with toluidine blue.

more organized with a mixture of fluorescent elongated fibroblasts and more rounded chondrocytic cells (Figure 6c). By day 30, the cells in the cartilaginous tissues, as confirmed by toluidine blue staining, were also predominantly GFP + (Figure 6d). These results show that in arthrofibrosis, myofibroblasts arise from fibroblastic cells resident in the connective tissues of the joint. These cells have a high proliferative capacity and the ability to transdifferentiate into chondrocytic cells.

\section{DISCUSSION}

These investigations present a vivid demonstration of the stimulatory capacity of TGF- $\beta 1$ and its potential as a profibrotic cytokine in joint disease. Sustained overexpression of TGF- $\beta 1$ in the knee joints of nude rats induced a severe fibrotic response arising from the rapid proliferation of synovial fibroblasts, their differentiation into myofibroblasts and the synthesis of fibrillar collagenous matrix. Much like the adhesions associated with arthrofibrosis in humans, the fibrotic tissue progressively developed an aggressive phenotype and began to attach and fuse with the cartilaginous and bony surfaces. Fibrotic regions in contact with articular cartilage began to undergo chondrometaplasia. Following 30 days of TGF- $\beta 1$ overexpression, sections of the expanded fibro-cartilaginous tissue had penetrated the articular cartilage and subchondral bone. Large portions of the hypertrophied expanse had differentiated into hyaline-like cartilage, progressing in some regions toward osteogenesis.

Although our data provide an extraordinarily severe representation of joint fibrosis, the pathologies observed are entirely consistent with those seen in clinical cases of arthrofibrosis that occur following joint surgery. ${ }^{29}$ Procedures involving the knee, such as anterior cruciate ligament reconstruction and high tibial osteotomy, are particularly vulnerable to the development of this type of fibrosis. ${ }^{29}$ Histological examination of tissues recovered from fibrotic knee joints following surgical release frequently identifies fibrosis, vascular proliferation and synovial chondrometaplasia. ${ }^{30}$ In many cases the fibro-chondrogenic tissues also contain endochondral bone formations. ${ }^{31-33}$ The similarities between the tissue phenotype of the rat TGF- $\beta 1$ overexpression model shown here and human arthrofibrosis, indicate that the data generated in the rat knee have relevance to the human condition. As such, our results support the role of TGF- $\beta 1$ as a primary mediator of the pathogenesis in arthrofibrosis and therefore, as a primary target in the prevention of fibrotic conditions of the joint.

\section{Expression Profiling is Consistent with an Aggressive Fibrotic and Chondrometaplastic Phenotype}

The expression data from the PCR-arrays support the macroscopic and histologic findings, and provide insight into the 
molecular events through which TGF- $\beta 1$ drives the fibrotic hypertrophy and cartilaginous morphogenesis of the tissues. Overall, the profile reflected in Table 1 is in accord with a highly mobile, aggressive tissue that produces large quantities of ECM protein. Similar to the histologic profile, the pattern of gene expression bears many similarities to that of an aggressive tumor.

Consistent with the fibrotic phenotype observed at days 5 and 10, there was an accompanying increase in expression of various laminins and ECM proteins, including interstitial collagens type I and III, and pericellular type V collagen. Further, as the tissue transitioned to hyaline-like cartilage, there was a dramatic enhancement of expression of collagen type II, the predominant structural protein of articular cartilage. This was paralleled by an increase in transcription of cartilage link protein (HAPLN1), which serves to stabilize aggrecan and hyaluronan aggregates in the articular cartilage matrix and contributes to chondrocyte differentiation and maturation. ${ }^{34}$

Beyond cellular proliferation and expression of structural proteins, the changes in tissue phenotype observed in response to TGF- $\beta 1$ stimulation require extensive degradation of pre-existing matrix as the emerging fibrotic tissue is generated and expands, and later as the fibrous mass becomes invasive and is replaced by cartilaginous tissue. In accordance with this, some of the more striking increases in gene expression were seen among the MMPs. Fibrosis has often been considered to be a process dominated by TIMPs, whereby increased inhibition of MMPs is thought to permit the accumulation of ECM proteins, leading to fibrotic hypertrophy ${ }^{35,36}$ Although TIMPs modulate MMP proteolysis, it is also known that TIMPs-1 and -2 facilitate the activation of certain MMPs. ${ }^{37}$ While we saw an early, but relatively modest, increase in TIMP-1 expression at day 5, dramatic increases were seen in MMPs-2, -7 -8, -9, -11, -12, -13, -14 and -16 , which further increased at day 10 . At various time points in the experiment, expression of certain MMPs was increased by 80 - to 300 -fold.

MMPs are known to participate in numerous diverse activities, including ECM remodeling, basement membrane disruption, epithelial apoptosis, cell migration and angiogenesis. ${ }^{38}$ Their roles in these processes occur either by direct matrix molecule cleavage or by generating bioactive mediators and biologic regulators. ${ }^{35,38}$ Owing to the complex and dynamic nature of the articular tissues over the 30-day experiment, it is not possible to discern the contributions of individual MMPs in arthrofibrosis. However, our results suggest that the induction and maintenance of arthrofibrosis does not hinge on the activity of any single MMP, but instead represents an orchestrated, interactive network between numerous MMPs and TIMPs.

Also notable was the marked increase in expression of matricellular protein genes. These non-structural, secreted glycoproteins interact with cell surface receptors, the ECM and soluble extracellular factors (eg, growth factors and
MMPs) to modulate cell function as well as regulate the activity or availability of proteins sequestered in the matrix. ${ }^{39}$ As a group, matricellular proteins are known to enhance cellular mobility, ECM synthesis, cellular differentiation and migration. ${ }^{40-44}$ They are expressed at high levels during development, but in healthy adults are typically only synthesized during active tissue remodeling, such as in wound repair and disease, particularly in cancer. Within this family, osteopontin showed the greatest induction throughout. Consistent with our expression data, osteopontin is known to bind and activate MMPs-2 and -3 even in the presence of TIMPs. ${ }^{45-48}$ Somewhat surprisingly, despite the dramatic effects of TGF- $\beta 1$ on the joint tissues, expression of CTGF remained relatively unchanged. CTGF is thought to be a major activator of TGF- $\beta 1$ activity and mediator of fibrosis in other tissues. ${ }^{14,49,50}$ Its relatively low induction here suggests that CTGF may not have a major role in arthrofibrosis, and that its absence may be compensated for by other members of this group.

The increased expression of both N-cadherin and NCAM throughout the 30-day experiment is consistent with the development of chondrometaplasia in the fibrotic tissues. These adhesion molecules are expressed during embryonal chondrogenesis, in which they contribute to early mesenchymal cell condensation..$^{51}$ Their enhanced expression is also in agreement with the aggressive phenotype of the expanded synovial tissues, as both molecules are known to contribute to enhanced cellular motility and migration and are associated with increased invasiveness in several types of cancer. $^{52,53}$

\section{TGF- $\beta 1$ and Synovial Pathology in Rheumatoid Arthritis} Although our investigations were based on TGF- $\beta 1$ and its contribution to arthrofibrosis, our results also support a key role for this cytokine in the pathogenesis of rheumatoid arthritis (RA). In RA, chronic autoimmune stimulation of the joints drives the dramatic expansion and activation of the synovial tissues, which form an aggressive pannus that invades and erodes the articular cartilage and subchondral bone. ${ }^{54}$ Increased expression of TGF- $\beta 1$ has been found in the synovial tissues of rheumatoid joints using immunohistochemistry, ${ }^{55,56}$ northern ${ }^{57}$ and western blot, ${ }^{58}$ and elevated TGF- $\beta 1$ levels have been found in synovial effusions. ${ }^{9,59}$ Further, synovial tissues from RA joints with high inflammation selectively display enhanced expression of genes in the TGF- $\beta 1$ pathway and an increased proportion of cells with a myofibroblast phenotype. ${ }^{60}$

Consistent with these findings, our data show that local overexpression of TGF- $\beta 1$ in the joint has the capacity to drive many aspects of RA pathology that are associated with synovial fibroblasts. These include hyperproliferation, differentiation into myofibroblasts, enhanced ECM deposition, motility, MMP production and cartilage invasion. Although it is likely that TGF- $\beta 1$ is an important mediator of fibroblast activity in RA, rheumatoid synovium is also characterized by 
a marked infiltration of immune and inflammatory cells. ${ }^{54}$ Despite showing a very robust response to TGF- $\beta 1$ stimulation, inflammatory cells were conspicuously absent in the joints of the experimental animals receiving Ad.TGF- $\beta 1$. Thus, unlike arthrofibrosis, in which TGF- $\beta 1$ appears to be the primary mediator of pathogenesis, in RA it appears to be more of a downstream contributor and remains only part of the complex cytokine milieu.

\section{Synovial and Capsular Fibroblasts have a High Proliferative Capacity and Innate Plasticity}

Following lentiviral-mediated delivery of the cDNA for GFP to the knees of rats, a large percentage of fibroblasts resident in the soft articular tissues surrounding the joint were fluorescently tagged. In a previously published study directed toward development of gene-based treatments for joint diseases, we characterized the cell types transduced by adenovirus and lentivirus vectors following intra-articular delivery. ${ }^{24}$ These studies showed that both vectors had very similar tropisms. The overwhelming majority of cells transduced by either vector was $\mathrm{CD} 90+, \mathrm{CD} 29+$, VCAM +, $\mathrm{CD} 11 \mathrm{~b}$ - fibroblasts and resided in the intimal, and subintimal layers of the synovium. The macrophage-like CD11b + cells, the other predominant cell type in the synovium, were not transduced at detectable levels by either vector. Chondrocytes in articular cartilage were also not transduced. Although chondrocytes are fairly amenable to infection with lenti- and adenovirus in vitro, the dense cartilage matrix surrounding these cells in their native context effectively occludes the viruses and prevents genetic modification in vivo.

For the experiments in this study, the adenovirus is used as a vehicle to deliver the TGF- $\beta 1$ cDNA to receptive cells inside the joint, which then become local factories to synthesize and secrete large quantities of the TGF- $\beta 1$ gene product into the joint fluids. The TGF- $\beta 1$ is then distributed throughout the joint to stimulate receptive cells in a paracrine manner. The lentivirus containing GFP, in contrast, is used to genetically mark the cells (primarily CD90 + fibroblasts) that were present in the joint before stimulation with TGF- $\beta$. As the virus stably integrates into the genome of the transduced cell, all progeny arising from these cells would similarly be GFP + and fluoresce green. ${ }^{24}$ After stimulation with TGF- $\beta 1$, these GFP + cells massively proliferated, and differentiated into myofibroblasts and later chondrocytic cells, such that the vast majority of cells in the expanded tissues fluoresced green. By stably pre-labeling the articular cells in this manner we showed that the immense fibrotic expansion of the synovium (and subsequent differentiation of the cells into chondrocytes) arises from cells resident to the joint space.

For pathologic fibrotic conditions in organs, such as the lung, kidney and liver, the fibroblast/myofibroblast populations responsible for generating the fibrotic mass are thought to originate variously from: (1) local, resident mesenchymal cell populations, (2) epithelial cells that undergo epithelial to mesenchymal transition and/or (3) circulating mesenchymal progenitors from bone marrow that home to sites of injury. ${ }^{61-65}$ With regard to arthrofibrosis, our data strongly support the first scenario, and largely exclude the other two as having a meaningful role. Further, our data provide a striking demonstration of the proliferative capacity, innate plasticity and chondro/osteogenic potential of synovial and capsular fibroblasts. They also confirm the potency of TGF- $\beta 1$ as an inducer of proliferation and chondrogenic differentiation in these cells.

The existence of mesenchymal progenitor cells in human synovium has been recognized since $2001,{ }^{66}$ and the natural potential of these cells to spontaneously generate ectopic cartilaginous/osteogenic tissue is reflected in diseases such as chondromatosis and arthrofibrosis. ${ }^{67,68}$ The utility of these cells in therapies for cartilage and bone repair is currently being investigated, and several preclinical studies point to synovial-derived fibroblasts as being superior to bone marrow and adipose-derived mesenchymal progenitors for these purposes. $^{69,70}$ The apparent facility with which articular fibroblasts differentiate along chondrogenic and osteogenic pathways suggest they are predisposed to these lineages and should be strongly considered as candidates for regenerative and tissue-engineering strategies for connective tissue disorders. In light of this, the application of TGF- $\beta 1$ as a chondrogenic agent in vivo, either as a recombinant protein or transgene product, should be more cautiously considered. The results of our in vitro experiments suggest that at peak levels of synthesis as much as $400-500 \mathrm{ng}$ of TGF- $\beta 1$ per $48 \mathrm{~h}$ may have been produced by the transduced cell population inside the joint. Although the actual expression profile of TGF $\beta 1$ intra-articularly over the 30 period remains unknown, our results serve to emphasize the sensitivity of connective tissue fibroblasts to exogenous growth factor stimulation, and that protocols designed to induce cellular differentiation in cartilage and bone repair in vivo should be aware of the capacity of these agents for toxic side effects in adjacent tissues.

\section{ACKNOWLEDGEMENT}

This work was supported in part by Grants AR050249, AR048566 from the National Institute of Arthritis and Musculoskeletal Skin Diseases.

\section{DISCLOSURE/CONFLICT OF INTEREST}

The authors declare no conflict of interest.

1. Gholve PA, Voellmicke KV, Guven M, et al. Arthrofibrosis of the knee after tibial spine fracture in children: a report of two complicated cases. Hss J 2008;4:14-19.

2. Lee SK, Gargano F, Hausman MR. Wrist arthrofibrosis. Hand Clin 2006;22:529-538; abstract vii.

3. Schiavone Panni A, Cerciello $S$, Vasso $M$, et al. Stiffness in total knee arthroplasty. J Orthop Traumatol 2009;10:111-118.

4. Boldt JG, Munzinger UK, Zanetti M, et al. Arthrofibrosis associated with total knee arthroplasty: gray-scale and power Doppler sonographic findings. AJR Am J Roentgenol 2004;182:337-340.

5. Neviaser RJ, Neviaser TJ. The frozen shoulder. Diagnosis and management. Clin Orthop Relat Res 1987;223:59-64.

6. Dias R, Cutts S, Massoud S. Frozen shoulder. Br Med J 2005;331: $1453-1456$. 
7. Hannafin JA, Chiaia TA. Adhesive capsulitis. A treatment approach. Clin Orthop Relat Res 2000;372:95-109.

8. Wynn TA. Cellular and molecular mechanisms of fibrosis. J Pathol 2008;214:199-210.

9. Pohlers D, Brenmoehl J, Loffler I, et al. TGF-beta and fibrosis in different organs-molecular pathway imprints. Biochim Biophys Acta 2009;1792:746-756.

10. Gressner OA, Rizk MS, Kovalenko E, et al. Changing the pathogenetic roadmap of liver fibrosis? Where did it start; where will it go? J Gastroenterol Hepatol 2008;23:1024-1035.

11. Border WA, Noble NA. Transforming growth factor beta in tissue fibrosis. N Engl J Med 1994;331:1286-1292.

12. Rahimi RA, Leof EB. TGF-beta signaling: a tale of two responses. J Cell Biochem 2007;102:593-608.

13. Leivonen SK, Kahari VM. Transforming growth factor-beta signaling in cancer invasion and metastasis. Int J Cancer 2007;121:2119-2124.

14. Ihn H. Pathogenesis of fibrosis: role of TGF-beta and CTGF. Curr Opin Rheumatol 2002;14:681-685.

15. Bonniaud P, Margetts PJ, Ask K, et al. TGF-beta and Smad3 signaling link inflammation to chronic fibrogenesis. J Immunol 2005;175: 5390-5395.

16. Takagawa S, Lakos G, Mori Y, et al. Sustained activation of fibroblast transforming growth factor-beta/Smad signaling in a murine model of scleroderma. J Invest Dermatol 2003;121:41-50.

17. Verrecchia F, Chu ML, Mauviel A. Identification of novel TGF-beta/ Smad gene targets in dermal fibroblasts using a combined cDNA microarray/promoter transactivation approach. J Biol Chem 2001;276: 17058-17062.

18. Verrecchia F, Mauviel A. Transforming growth factor-beta signaling through the Smad pathway: role in extracellular matrix gene expression and regulation. J Invest Dermatol 2002;118:211-215.

19. Holmes A, Abraham DJ, Sa S, et al. CTGF and SMADs, maintenance of scleroderma phenotype is independent of SMAD signaling. J Biol Chem 2001;276:10594-10601.

20. Rodeo SA, Hannafin JA, Tom J, et al. Immunolocalization of cytokines and their receptors in adhesive capsulitis of the shoulder. J Orthop Res 1997:15:427-436.

21. Ryu JD, Kirpalani PA, Kim JM, et al. Expression of vascular endothelial growth factor and angiogenesis in the diabetic frozen shoulder J Shoulder Elbow Surg 2006;15:679-685.

22. Hardy S, Kitamura M, Harris-Stansil T, et al. Construction of adenovirus vectors through Cre-lox recombination. J Virol 1997;71:1842-1849.

23. $\mathrm{Ng} \mathrm{P,} \mathrm{Graham} \mathrm{FL.} \mathrm{Construction} \mathrm{of} \mathrm{first-generation} \mathrm{adenoviral} \mathrm{vectors.}$ Methods Mol Med 2002;69:389-414.

24. Gouze E, Gouze JN, Palmer GD, et al. Transgene persistence and cell turnover in the diarthrodial joint: implications for gene therapy of chronic joint diseases. Mol Ther 2007;15:1114-1120.

25. Spessotto $P$, Cervi $M$, Mucignat $M T$, et al. Beta 1 integrin-dependent cell adhesion to EMILIN-1 is mediated by the $\mathrm{gClq}$ domain. J Biol Chem 2003;278:6160-6167.

26. Zhang HY, Gharaee-Kermani M, Zhang K, et al. Lung fibroblast alpha-smooth muscle actin expression and contractile phenotype in bleomycin-induced pulmonary fibrosis. Am J Pathol 1996;148: 527-537.

27. Gouze $\mathrm{E}$, Pawliuk R, Pilapil $\mathrm{C}$, et al. In vivo gene delivery to synovium by lentiviral vectors. Mol Ther 2002;5:397-404.

28. Gouze E, Pawliuk R, Gouze JN, et al. Lentiviral-mediated gene delivery to synovium: potent intra-articular expression with amplification by inflammation. Mol Ther 2003;7:460-466.

29. Magit D, Wolff A, Sutton K, et al. Arthrofibrosis of the knee. J Am Acad Orthop Surg 2007:15:682-694.

30. Murphey MD, Vidal JA, Fanburg-Smith JC, et al. Imaging of synovial chondromatosis with radiologic-pathologic correlation. Radiographics 2007;27:1465-1488.

31. Vargas-Gonzalez R, Sanchez-Sosa S. Fibrocartilaginous dysplasia (fibrous dysplasia with extensive cartilaginous differentiation). Pathol Oncol Res 2006;12:111-114.

32. Zoricic S, Maric I, Bobinac D, et al. Expression of bone morphogenetic proteins and cartilage-derived morphogenetic proteins during osteophyte formation in humans. J Anat 2003;202:269-277.

33. Matsui $Y$, Hasegawa T, Kubo T, et al. Intrapatellar tendon lipoma with chondro-osseous differentiation: detection of HMGA2-LPP fusion gene transcript. J Clin Pathol 2006;59:434-436.
34. Wirrig EE, Snarr BS, Chintalapudi MR, et al. Cartilage link protein 1 (Crtl1), an extracellular matrix component playing an important role in heart development. Dev Biol 2007;310:291-303.

35. Gueders MM, Foidart JM, Noel A, et al. Matrix metalloproteinases (MMPs) and tissue inhibitors of MMPs in the respiratory tract: potential implications in asthma and other lung diseases. Eur J Pharmacol 2006;533:133-144.

36. Hemmann S, Graf J, Roderfeld M, et al. Expression of MMPs and TIMPs in liver fibrosis - a systematic review with special emphasis on antifibrotic strategies. J Hepatol 2007;46:955-975.

37. English JL, Kassiri Z, Koskivirta I, et al. Individual Timp deficiencies differentially impact pro-MMP-2 activation. J Biol Chem 2006;281: 10337-10346.

38. Pardo A, Selman M. Matrix metalloproteases in aberrant fibrotic tissue remodeling. Proc Am Thorac Soc 2006;3:383-388.

39. Bornstein $\mathrm{P}$, Sage EH. Matricellular proteins: extracellular modulators of cell function. Curr Opin Cell Biol 2002;14:608-616.

40. Alford $\mathrm{Al}$, Hankenson KD. Matricellular proteins: extracellula modulators of bone development, remodeling, and regeneration. Bone 2006;38:749-757.

41. Mo FE, Lau LF. The matricellular protein CCN1 is essential for cardiac development. Circ Res 2006;99:961-969.

42. Moura R, Tjwa M, Vandervoort $P$, et al. Thrombospondin-1 activates medial smooth muscle cells and triggers neointima formation upon mouse carotid artery ligation. Arterioscler Thromb Vasc Biol 2007;27:2163-2169.

43. Bradshaw AD, Sage EH. SPARC, a matricellular protein that functions in cellular differentiation and tissue response to injury. J Clin Invest 2001; 107:1049-1054.

44. Bornstein P. Matricellular proteins: an overview. Matrix Biol 2000;19:555-556.

45. Agnihotri $\mathrm{R}, \mathrm{Crawford} \mathrm{HC}$, Haro $\mathrm{H}$, et al. Osteopontin, a novel substrate for matrix metalloproteinase-3 (stromelysin-1) and matrix metalloproteinase-7 (matrilysin). J Biol Chem 2001;276:28261-28267.

46. Pardo A, Gibson K, Cisneros J, et al. Up-regulation and profibrotic role of osteopontin in human idiopathic pulmonary fibrosis. PLoS Med 2005;2:e251.

47. Castellano G, Malaponte G, Mazzarino MC, et al. Activation of the osteopontin/matrix metalloproteinase-9 pathway correlates with prostate cancer progression. Clin Cancer Res 2008;14:7470-7480.

48. Gao YA, Agnihotri R, Vary CP, et al. Expression and characterization of recombinant osteopontin peptides representing matrix metaIloproteinase proteolytic fragments. Matrix Biol 2004;23:457-466.

49. Kobayashi $\mathrm{T}$, Inoue $\mathrm{T}$, Okada $\mathrm{H}$, et al. Connective tissue growth factor mediates the profibrotic effects of transforming growth factor-beta produced by tubular epithelial cells in response to high glucose. Clin Exp Nephrol 2005;9:114-121.

50. Leask A, Parapuram SK, Shi-Wen X, et al. Connective tissue growth factor (CTGF, CCN2) gene regulation: a potent clinical bio-marker of fibroproliferative disease? J Cell Commun Signal 2009;3:89-94.

51. Woods A, Wang G, Beier F. Regulation of chondrocyte differentiation by the actin cytoskeleton and adhesive interactions. J Cell Physiol 2007;213:1-8.

52. Lehembre $F$, Yilmaz $M$, Wicki $A$, et al. NCAM-induced focal adhesion assembly: a functional switch upon loss of E-cadherin. Embo J 2008;27:2603-2615.

53. Frame MC, Inman GJ. NCAM is at the heart of reciprocal regulation of E-cadherin- and integrin-mediated adhesions via signaling modulation. Dev Cell 2008;15:494-496.

54. Bartok B, Firestein GS. Fibroblast-like synoviocytes: key effector cells in rheumatoid arthritis. Immunol Rev 2010;233:233-255.

55. Chu CQ, Field M, Abney E, et al. Transforming growth factor-beta 1 in rheumatoid synovial membrane and cartilage/pannus junction. Clin Exp Immunol 1991;86:380-386.

56. Szekanecz Z, Haines GK, Harlow LA, et al. Increased synovial expression of transforming growth factor (TGF)-beta receptor endoglin and TGF-beta 1 in rheumatoid arthritis: possible interactions in the pathogenesis of the disease. Clin Immunol Immunopathol 1995;76:187-194.

57. Taketazu F, Kato M, Gobl A, et al. Enhanced expression of transforming growth factor-beta $s$ and transforming growth factor-beta type II receptor in the synovial tissues of patients with rheumatoid arthritis. Lab Invest 1994;70:620-630.

58. Goddard DH, Grossman SL, Williams WV, et al. Regulation of synovia cell growth. Coexpression of transforming growth factor beta and 
basic fibroblast growth factor by cultured synovial cells. Arthritis Rheum 1992;35:1296-1303.

59. Fava $\mathrm{R}$, Olsen $\mathrm{N}$, Keski-Oja J, et al. Active and latent forms of transforming growth factor beta activity in synovial effusions. J Exp Med 1989;169:291-296.

60. Kasperkovitz PV, Timmer TC, Smeets TJ, et al. Fibroblast-like synoviocytes derived from patients with rheumatoid arthritis show the imprint of synovial tissue heterogeneity: evidence of a link between an increased myofibroblast-like phenotype and highinflammation synovitis. Arthritis Rheum 2005;52:430-441.

61. Shintani N, Hunziker EB. Chondrogenic differentiation of bovine synovium: bone morphogenetic proteins 2 and 7 and transforming growth factor beta1 induce the formation of different types of cartilaginous tissue. Arthritis Rheum 2007;56:1869-1879.

62. Fiorito S, Magrini L, Adrey J, et al. Inflammatory status and cartilage regenerative potential of synovial fibroblasts from patients with osteoarthritis and chondropathy. Rheumatology (Oxford) 2005;44:164-171.

63. Mochizuki T, Muneta T, Sakaguchi $Y$, et al. Higher chondrogenic potential of fibrous synovium- and adipose synovium-derived cells compared with subcutaneous fat-derived cells: distinguishing properties of mesenchymal stem cells in humans. Arthritis Rheum 2006;54:843-853.
64. Shirasawa S, Sekiya I, Sakaguchi Y, et al. In vitro chondrogenesis of human synovium-derived mesenchymal stem cells: optimal condition and comparison with bone marrow-derived cells. J Cell Biochem 2006;97:84-97.

65. Jiang $X, C$ ui $P, C h e n ~ W$, et al. [Study on the directed inducing process of cartilage cells differentiated from human marrow mesenchymal stem cells]. Zhonghua Er Bi Yan Hou Ke Za Zhi 2002;37: 137-139.

66. De Bari C, Dell'Accio F, Tylzanowski P, et al. Multipotent mesenchymal stem cells from adult human synovial membrane. Arthritis Rheum 2001;44:1928-1942.

67. Karystinou A, Dell'Accio F, Kurth TB, et al. Distinct mesenchymal progenitor cell subsets in the adult human synovium. Rheumatology (Oxford) 2009;48:1057-1064.

68. Crawford A, Frazer A, Lippitt JM, et al. A case of chondromatosis indicates a synovial stem cell aetiology. Rheumatology (Oxford) 2006;45:1529-1533.

69. Krampera M, Pizzolo G, Aprili G, et al. Mesenchymal stem cells for bone, cartilage, tendon and skeletal muscle repair. Bone 2006;39: 678-683.

70. Ahmed N, Stanford WL, Kandel RA. Mesenchymal stem and progenitor cells for cartilage repair. Skeletal Radiol 2007;36:909-912. 